\title{
Educação para o desenvolvimento sustentável: o papel da Universidade
}

Education for sustainable development: the role of University Educación ambiental:el papel de la Universidad

\author{
Ronise Straiotto PIATO ${ }^{1}$ \\ Maria Isabel ALVES REZENDE ${ }^{2}$ \\ Lucas de Souza LEHFELD ${ }^{3}$ \\ Renato Salviato FAJARDO ${ }^{4}$ \\ Maria Cristina Rosifini ALVES REZENDE ${ }^{5}$
}

\begin{abstract}
${ }^{\prime}$ Graduação em Odontologia, Faculdade de Odontologia de Araçatuba, Universidade Estadual Paulista “Júlio de Mesquita Filho”, UNESP, Brasil ${ }^{2}$ Graduação em Direito, Faculdade Laudo de Camargo, Universidade de Ribeirão Preto, Brasil

\section{Resumo}

A Universidade responde pela formação de cidadãos com pensamento crítico, fundamentado em conceitos atualizados, capazes de favorecer uma postura dinâmica e participativa deste profissional na comunidade na qual estará inserido. A educação para o desenvolvimento sustentável, permeada pela articulação entre o conhecimento e os fenômenos sociais e culturais, traz consigo o desafio de incorporar habilidades, conferindo valores indispensáveis não só para o entendimento das relações históricas entre o ser humano e o ambiente, como também para a melhoria da qualidade de vida. A "Declaração Mundial sobre a Educação Superior para o Século XXI - Visão e Ação" pauta o processo educativo por sua missão em formar profissionais cidadãos, altamente esclarecidos, motivados, integrados e aptos a criarem uma sociedade fundamentada no amor à humanidade e na sabedoria. O equilíbrio entre as funções básicas de ensino, pesquisa e extensão dentro da Universidade concorre para que o educando se aproprie da construção de seu próprio conhecimento em uma perspectiva de formação integral do ser humano, ciente de sua responsabilidade social e política em prol de uma sociedade ambientalmente saudável. O presente trabalho tem o objetivo de, orientado pela revisão de literatura, construir algumas considerações sobre o papel da Universidade na educação para a sustentabilidade.

Descritores: Universidades; Educação Superior; Educação Ambiental.

\section{Abstract}

The University is responsible for the stablishment of citizens with critical thinking, based on current concepts, capable of a dynamic and participative attitude in the community in which these professinals will be inserted. Education at environmental sustainability, permeated by the articulation among knowledge, social, and cultural phenomena, brings the challenge of incorporating skills, providing essential values not only for understanding the historical relations between human beings and the environment, but also to improving the quality of life. The "World Conference on Higher Education in the Twenty-first Century: Vision and Action" guides the educational process by its mission to train citizens professionals, highly informed, motivated, integrated and able to create a society based on love of humanity and wisdom. The balancing among the basic functions of teaching, research and extension within the University contributes to the student to take ownership of the construction of his own knowledge in a perspective of integral formation of the human being, aware of his social responsibility and policy for a society environmentally sound. This paper aims to, guided by literature review, present some considerations on the role of the University in education for environmental sustainability.

Descriptors: Universities; Education, Higher; Education, Environmental.

\section{Resumen}

La Universidad es responsable por la formación de ciudadanos con pensamiento crítico, basado en los conceptos actuales, capaces de una actitud dinámica y participativa en la comunidad en la que se inserta. Educación para la sostenibilidad del medio ambiente permite la articulación entre el conocimiento y fenómenos sociales y culturales, trae consigo el reto de incorporar habilidades, proporcionando valores esenciales no sólo para la comprensión de las relaciones históricas entre los seres humanos y el medio ambiente, sino también a mejorar la calidad de vida. La "Conferencia Mundial sobre la Educación Superior en el Siglo XXI: Visión y Acción" guía el proceso educativo por su misión de formar ciudadanos profesionales, altamente informado, motivado, integrado y capaz de crear una sociedad basada en el amor de la humanidad y la sabiduría. El equilibrio entre las funciones básicas de docencia, investigación y extensión dentro de la Universidad contribuye al estudiante a tomar posesión de la construcción de su propio conocimiento, en una perspectiva de la formación integral del ser humano, consciente de su responsabilidad social y política de una sociedad el medio ambiente. Este trabajo pretende, guiada por revisión de la literatura, para presentar algunas consideraciones sobre el papel de la Universidad en la educación para la sostenibilidad ambiental.

Descriptores: Universidades; Educación Superior; Educación Ambiental.

\section{INTRODUÇÃO}

No Brasil, a Política Nacional de Educação Ambiental - Lei $n^{\circ}$ 9795/1999, em seu Artigo $1^{\text {o }}$ estabelece que "entendem-se por educação ambiental os processos por meio dos quais o indivíduo e a coletividade constroem valores sociais, conhecimentos, habilidades, atitudes e competências voltadas para a conservação do meio ambiente, bem de uso comum do povo, essencial à sadia qualidade de vida e sua sustentabilidade" ${ }^{1}$.

As Conferências de Estocolmo, em 1972, Belgrado (1975), Tbilisi (1977), Moscou (1987), Rio de Janeiro (1992), Tessalônica (1997), Rio+20 (2012) trouxeram em pauta a discussão da educação ambiental como um processo dialético de reconhecimento de valores e clarificação de conceitos, na busca de adoção de novos padrões de atitudes. Sato ${ }^{2}$ destaca que a educação ambiental está vinculada à prática das tomadas de decisões e a ética que conduzem para a melhoria da qualidade de vida. Sorrentino et al. ${ }^{3}$ lembram que a educação ambiental surge como importante estratégia de enfrentamento da crise civilizatória de dupla ordem, cultural e social. Segundo Morales ${ }^{4}$, como componente formador, a educação ambiental se mostra essencial no processo de ruptura de paradigmas e na articulação de novas concepções do ambiente. 
O termo educação ambiental (environmental education) foi utilizado pela primeira vez em 1965 durante a reunião The Keele Conference on Education and the Countryside, promovida pela Universidade de Keele, na Grã-Bretanha. Durante o evento a educação ambiental foi discutida atrelada à ecologia e sob ótica eminentemente preservacionista ${ }^{5}$.

A Assembleia Geral das Nações Unidas com base na resolução $n^{\circ}$ 57/254 instituiu a "Década das Nações Unidas da Educação para o Desenvolvimento Sustentável" (2005-2014) com o propósito de estimular estratégias articuladas que permitissem à educação respostas às crises ambiental, social e econômica. Criaram-se assim condições que encorajaram os Estados-membros da ONU (entre eles o Brasil) a promoverem a integração dos valores do desenvolvimento sustentável em todas as formas de aprendizagem, abrindo perspectivas de diálogo entre os parceiros empenhados e com responsabilidades na construção de sociedades mais equilibradas ambiental, social e economicamente ${ }^{6}$.

A educação para o desenvolvimento sustentável confere aos indivíduos as ferramentas necessárias para enfrentar os desafios do seu cotidiano, porquanto incorpora habilidades significativas no âmbito de um conjunto de valores indispensáveis ao desenvolvimento sustentável.

$\mathrm{Jacobi}^{7}$ destaca que a reflexão em torno das práticas sociais, dentro de um contexto marcado pela permanente degradação do meio ambiente, incide obrigatoriamente na articulação com a produção de sentidos sobre a educação ambiental.

Para Guimarães e Tomazello $^{8}$ formar profissionais educados para sustentabilidade impacta fortemente na qualidade do meio ambiente e na qualidade de vida de uma sociedade mais justa.

Sato e Santos $^{9}$ acrescentam que esta formação pode ser entendida e aceita como fatorchave no enfrentamento da crise planetária do século XXI.

O propósito deste trabalho é aprofundar a discussão sobre o papel motivador e prescritivo da universidade na educação para sustentabilidade dos profissionais que coloca no mercado.

\section{REVISÃO DA LITERATURA}

\section{- A formação do profissional cidadão}

A Universidade se consagra, desde a sua criação na Idade Média, como espaço agregador de inúmeros saberes heterogêneos e por seu forte compromisso com a transformação da sociedade enquanto instrumento de formação $e$ desenvolvimento de indivíduos ${ }^{10}$.

Segundo Menezes Neto ${ }^{11}$ as expressões deste compromisso são identificadas pelas ações de pesquisa, ensino e extensão, consideradas atividades básicas na Universidade, garantindo a formação de um profissional cidadão comprometido com a realidade social.

A integração entre ensino, pesquisa e extensão envolve o domínio não apenas do conhecimento produzido e acumulado dentro dos muros da Universidade, como também suas aplicações pontuais imediatas dentro de um contexto de como este conhecimento é produzido, sistematizado e empreendido no processo de transformação social ${ }^{12}$.

Nunes e Silva $^{13}$ destacam que a extensão universitária promove a interação entre a universidade e a comunidade na qual ela está inserida, estabelecendo uma ponte permanente com os diversos setores da sociedade.

Via de mão dupla, a extensão universitária leva conhecimentos e/ou assistência à comunidade $\mathrm{e}$ recebe dela ofeedback das suas reais necessidades, retroalimentando a pesquisa, que por sua vez retroalimenta o ensino ${ }^{12,14}$.

Também a Universidade recebe $\mathrm{o}$ aprendizado advindo do saber das comunidades com as quais se socializa. Troca de saberes e valores, portanto, já que a Universidade influencia e é influenciada pela comunidade ${ }^{14}$.

Para Botomé ${ }^{15}$ a Universidade deve não só produzir conhecimento social e científico que sejam relevantes, como também torná-lo acessível a todos. O papel da Universidade neste novo milênio apoia-se fortemente na extensão universitária, por ser instrumento sensível na percepção e inclusão das necessidades da comunidade na criação e recriação do conhecimento ${ }^{13,16}$.

\section{- Sustentabilidade na educação universitária}

A Educação pode ser compreendida como um processo de transmissão cultural de valores, normas, atitudes, experiências, imagens e representações com função de reprodução do sistema social $^{17}$.

Este processo não pode em absoluto estar excluído dos debates que cercam a sustentabilidade das atividades do homem já que, ao longo dos séculos, importantes falhas pedagógicas na preparação do cidadão para uma sociedade sustentável permitiram que se instalasse o atual alarme ambiental e social ${ }^{18}$.

A Educação Universitária, desde seus primórdios, tem a missão de criar, transmitir e disseminar o conhecimento ${ }^{19}$. Bernheim e Chauí ${ }^{20}$ lembram que na sociedade contemporânea o conhecimento e a informação nos processos de produção representam um novo paradigma econômico, a despeito da disponibilidade de capital, trabalho, matérias-primas ou energia.

Segundo $A \min ^{21}$ o uso competitivo do conhecimento e das inovações tecnológicas fundamentam as economias mais avançadas, tornando o conhecimento um pilar da riqueza e do 
poder das nações.

A Declaração Mundial sobre a Educação Superior para o Século XXI - Visão e Ação ${ }^{22}$ define a abrangência da missão social da educação superior contemporânea nas seguintes vertentes: (a) Avaliação da pertinência da educação superior fundamentada na adequação entre o que a sociedade espera da Universidade e o que esta retorna, com base em padrões éticos, imparcialidade política, capacidade crítica e, ao mesmo tempo e articulação entre problemas da comunidade e o conhecimento gerado, respeitados a cultura e a proteção ambiental; b) Prestação de serviço à comunidade, por meio de abordagem transdisciplinar e interdisciplinar, perseguindo a erradicação da pobreza, intolerância, violência, analfabetismo, fome, doença e degradação ambiental; c) Contribuição para o desenvolvimento e capacitação de todo o sistema educacional, aperfeiçoando as estruturas curriculares; d) Fortalecimento de seu papel na formação de profissionais cidadãos, altamente esclarecidos, motivados, integrados e aptos a criarem uma sociedade fundamentada no amor à humanidade e na sabedoria. $\mathrm{O}$ equilíbrio entre as funções básicas de ensino, pesquisa e extensão dentro da Universidade concorre para a formação de profissionais aptos a contribuir para o progresso, democratização e disseminação do conhecimento ${ }^{20}$.

No Brasil, desde 1997, os Parâmetros Curriculares Nacionais estabelecem a abordagem ambiental em um eixo transversal no processo educativo $^{23,24}$ e a maior parte das iniciativas no ensino superior têm se concentrados na ambientalização dos currículos e no incremento da investigação ambiental, com pouco ou nenhum respaldo dos principais decisores, e, na quase ausência de políticas públicas integradoras de educação e sustentabilidade ${ }^{25}$.

A Educação para a sustentabilidade no ensino superior não pode ser considerada apenas um processo de mudança curricular mas sim um redimensionar das questões ambientais equacionando um novo foco de atenção na universidade que envolva docentes, discentes, servidores técnicoadministrativos, gestores, disciplinas, departamentos, cursos, grades curriculares, projetos de pesquisa e extensão e comunidade na qual a universidade está inserida ${ }^{24}$.

Buarque $^{26}$ acredita que a Universidade precisa se transformar e reinventar para que possa servir a um projeto alternativo de civilização e definir os rumos do futuro. Para Dias ${ }^{27}$ parece inadmissível que uma política ambiental definida, traduzida por consistentes programas de educação para gestão ambiental, não esteja incluída em todas as ações das instituições de educação, ensino e pesquisa.

Carvalho $^{28}$ ressalta que três dimensões precisam ser consideradas com relação à educação para sustentabilidade: a)conhecimento, para que os fatos, conceitos e processos possam ser compreendidos; b)valores éticos e estéticos, para a construção de novos padrões de relação homemmeio; c)participação política, para o desenvolvimento da cidadania.

Janke e Tozoni-Reis ${ }^{29}$ acreditam que é preciso que se entenda que a Educação para Sustentabilidade se inscreve no horizonte educacional muito menos no seu contexto produtor, uma vez que não parece possível produzir o "profissional consciente", e muito mais no seu contexto promotor, o qual introduz e capacita o indivíduo quanto à contextualização histórica, conhecimento dos condicionantes sociais, atuação consciente frente ao ambiente e reconhecimento da complexa rede de interações desta problemática.

Para Grun $^{30}$ o redimensionamento do lugar do homem no planeta precede a conservação do meio ambiente, o que ao final se resume em uma questão de valores. A educação para a sustentabilidade se alija do corpo de conhecimentos e valores nos quais o ambiente tem valor utilitário para o homem. Valores considerados universais no contexto social se mostram desejáveis nesse processo educativo: justiça, igualdade, equidade e solidariedade ${ }^{31}$.

Esse processo de reconhecimento de valores e clarificação de conceitos, fundamentado no desenvolvimento de habilidades e atitudes em relação ao meio, traz consigo entendimento e apreciação das relações dos seres humanos articulados entre si, com suas culturas e seu meio biofísico, contribuindo para a tomada de posições éticas com vistas à promoção da qualidade de vida ${ }^{32}$. Também responde pela compreensão fundamental da presença humana no ambiente, da responsabilidade individual do cidadão e do seu papel crítico como pertencente a uma nação e um planeta ${ }^{33}$.

CONCLUSÃO

A sustentabilidade ambiental impõe mudanças no processo de ensino/aprendizagem da Universidade. Falhas pedagógicas importantes no ensino superior no decorrer dos anos, somadas à aplicação sem critério ético ambiental do conhecimento gerado e acumulado dentro dos muros do campus contribuíram para o status quo de uma sociedade em estado de risco. Ensino, Pesquisa, Extensão e Gestão se articulam na ambientalização da Universidade contemporânea, aberta, integradora e criativa, focada nos problemas e demandas da comunidade na qual está inserida.

\section{REFERÊNCIAS}

1. Brasil. Identidades da Educação ambiental Brasileira. Brasília: DEA/MMA, 2004.

2. Sato M. Educação Ambiental. São Carlos: Rima, 2002. 
3. Sorrentino M, Trajber R, Mendonça P, ferraro Jr. LA. Educação ambiental como política pública. Educ Pesq. 2005;31(2):285-99.

4. Morales AGM. A formação do profissional educador ambiental [tese]. Curitiba: Programa em Meio Ambiente e Desenvolvimento, Universidade Federal do Paraná; 2007.

5. Carvalho ICM. Educação ambiental: a formação do sujeito ecológico. São Paulo: Cortez; 2004.

6. Gomes MAC. Educação para o Desenvolvimento Sustentável no contexto da década: discursos e práticas no ensino básico.[tese]. Lisboa: Instituto de Geografia e Ordenamento do Território, Universidade de Lisboa; 2012.

7. Jacobi P. Educação ambiental: cidadania e sustentabilidade. Cad Pesqui. 2003;118(3):189205.

8. Guimaraes SSM, Tomazello MGC. A formação universitária para o ambiente: educação para a sustentabilidade. Ambiente e Educação. 2003, 5571, 2003

9. Sato M, Santos JE. A contribuição da educação ambiental à esperança de Pandora. São Carlos: Rima Editora, 2001.

10. Piato RS, Capalbo LC, Alves Rezende MIR, Lehfeld LS, Alves Rezende MCR. O papel da Universidade Aberta à Terceira Idade na educação ambiental. Arch Health Invest. 2014;3(5):66-71.

11.Menezes Neto PE. Universidade: ação e reflexão. Fortaleza: Edições UFC Imprensa Universitária, 1983.

12.Pivetta HMF, Backes DS, Carper A, Battistes ALHT, Marchiori M. Ensino, pesquisa e extensão universitária: em busca de uma integração efetiva. Linhas Críticas 2010;16(31):377-90.

13.Nunes ALPF, Silva MBC. A extensão universitária no ensino superior e a sociedade. Mal-Estar e Sociedade. 2011;4(7)::119-33.

14. Silva O. O que é extensão universitária. Integração: ensino, pesquisa e extensão. 1997;3(9):148-9.

15.Botomé SP. Pesquisa alienada e ensino alienante. O equívoco da extensão universitária. Petrópolis: Vozes, 1996.

16. Soares VLA. O papel social das IES: contribuição do ensino superior particular. Rev CESA. 2003;6:8.

17.Noé A. A relação educação e sociedade. Os fatores sociais que intervêm no processo educativo. Avaliação. 2000;5(3)21-6.

$\begin{array}{ccccr}\begin{array}{c}\text { 18. Sangari } \\ \text { sustentabilidade. }\end{array} & & \begin{array}{r}\text { educação } \\ \text { Disponível }\end{array} & & \text { em }\end{array}$ http://www.conexaoprofessor.

rj.gov.br/especial.asp?

EditeCodigoDaPagina=505. Acesso em 01 de junho de 2014.

19.Gacel-Ávila J. La internacionalización de la educación superior: paradigma para la ciudadanía global. Guadalajara: Universidad de Guadalajara, 2003.

20.Bernheim CT, Chaui MS. Challenges of the university in the knowledge society, five years after the World. Conference on Higher Education. Paris: UNESCO, 2003. Série Documentos Ocasionais de Fórum da UNESCO.

21.Amin S. Capitalism in the age of globalization: the management of contemporary society. London: Zed Books, 1997.

22. World Conference on Higher Education in the Twenty-first Century: Vision and Action; Paris; 1998. Paris: UNESCO, 1998.

23.Brasil. Ministério da Educação. Secretaria de Educação Fundamental. Parâmetros curriculares nacionais: Vol. 1 - Introdução aos Parâmetros Curriculares Nacionais. Brasília: MEC/SEF, 1997.

24.Brasil. Ministério da Educação. Secretaria de Educação Fundamental. Parâmetros curriculares nacionais: Vol. 8 - Apresentação dos Temas Transversais e Ética. Brasília: MEC/SEF, 1997.

25. Marcomin FE, Silva ADV. A sustentabilidade no ensino superior brasileiro: alguns elementos a partir da prática de educação ambiental na Universidade. Contrapontos. 2009;9(2):104-17.

26. Buarque C. La cortina de oro: los sustos técnicos $y$ sociales de fin de siglo y un sueño para el próximo, Brasilia: Comunica, 1997.26

27.Dias GB. Educação ambiental: princípios e práticas. São Paulo, Gaia, 1998.

28. Carvalho IA. Invenção ecológica. Porto Alegre: Editora da UFRGS, 2001.

29.Janke N, Tozoni-Reis MFC. Produção coletiva de conhecimentos sobre qualidade de vida: por uma educação ambiental participativa e emancipatória. Ciência \& Educação 2008; 14(1):147-57.

30.Grün M. Ética e Educação ambiental: a conexão necessária. Campinas: Papirus, 1996.

31. Bonotto DMB. Contribuições para o trabalho com valores em educação ambiental. Ciênc educ. 2008;14(2):295-306.

32. Sato M, Carvalho ICM. Educação Ambiental Pesquisa e Desafios. Porto Alegre: Artmed, 2005. p. 11-15.

33.Roos A, Becker ELS. Educação ambiental e sustentabilidade. Reget. 2012;5(5)857-66. 
http://dx.doi.org/10.21270/archi.v3i6.87

\section{CONFLITO DE INTERESSES}

Os autores declaram não haver conflitos de interesse.

\section{AUTOR PARA CORRESPONDENCIA}

\section{Maria Cristina Rosifini Alves Rezende}

rezende@foa.unesp.br

Submetido em 03/10/2014

Aceito em 18/10/2014 